\title{
Mobile Phone Interventions for Sleep Disorders and Sleep Quality: Systematic Review
}

Jong Cheol Shin ${ }^{1}$, MS; Julia Kim ${ }^{2}, \mathrm{RD}, \mathrm{MPH}$; Diana Grigsby-Toussaint ${ }^{1,2}, \mathrm{MPH}, \mathrm{PhD}$

${ }_{1}^{1}$ Department of Kinesiology and Community Health, University of Illinois-Urbana Champaign, Champaign, IL, United States

${ }^{2}$ Division of Nutritional Sciences, University of Illinois-Urbana Champaign, Urbana, IL, United States

\section{Corresponding Author:}

Diana Grigsby-Toussaint, MPH, PhD

Department of Kinesiology and Community Health

University of Illinois-Urbana Champaign

1206 S Fourth Street

Champaign, IL, 61820

United States

Phone: 12173339207

Fax: 12173332765

Email: dgrigs1@illinois.edu

\section{Abstract}

Background: Although mobile health technologies have been developed for interventions to improve sleep disorders and sleep quality, evidence of their effectiveness remains limited.

Objective: A systematic literature review was performed to determine the effectiveness of mobile technology interventions for improving sleep disorders and sleep quality.

Methods: Four electronic databases (EBSCOhost, PubMed/Medline, Scopus, and Web of Science) were searched for articles on mobile technology and sleep interventions published between January 1983 and December 2016. Studies were eligible for inclusion if they met the following criteria: (1) written in English, (2) adequate details on study design, (3) focus on sleep intervention research, (4) sleep index measurement outcome provided, and (5) publication in peer-reviewed journals.

Results: An initial sample of 2679 English-language papers were retrieved from five electronic databases. After screening and review, 16 eligible studies were evaluated to examine the impact of mobile phone interventions on sleep disorders and sleep quality. These included one case study, three pre-post studies, and 12 randomized controlled trials. The studies were categorized as (1) conventional mobile phone support and (2) utilizing mobile phone apps. Based on the results of sleep outcome measurements, 88\% (14/16) studies showed that mobile phone interventions have the capability to attenuate sleep disorders and to enhance sleep quality, regardless of intervention type. In addition, mobile phone intervention methods (either alternatively or as an auxiliary) provide better sleep solutions in comparison with other recognized treatments (eg, cognitive behavioral therapy for insomnia).

Conclusions: We found evidence to support the use of mobile phone interventions to address sleep disorders and to improve sleep quality. Our findings suggest that mobile phone technologies can be effective for future sleep intervention research.

(JMIR Mhealth Uhealth 2017;5(9):e131) doi: 10.2196/mhealth.7244

\section{KEYWORDS}

mHealth; apps; mobile health; sleep

\section{Introduction}

Sleep disorders are an important public health problem that affects approximately 50 to 70 million people in the United States [1]. Sleep disorders are defined as having abnormal sleep behaviors, including insomnia, sleep apnea, restless leg syndrome, and narcolepsy [2]. Those who have chronic sleep

disorders are at a greater risk for obesity, diabetes, hypertension, cardiovascular disease, stroke, and depression [3-6].

In addition to sleep disorders, insufficient sleep and irregular sleep patterns are also risk factors for obesity [7], impaired cardiovascular function [8,9], and diabetes [10]. According to the 2011-2014 report from the National Center for Health Statistics [11], 31.7\% of US adults do not meet the National Sleep Foundation's recommendation for at least 7 hours of sleep 
per night. Moreover, the 2011 Sleep in America poll reported that $63 \%$ of Americans did not meet the recommendations for sleep time during weekdays [12]. Given that sleep disorders and insufficient sleep increase the risk for chronic diseases, sleep interventions that improve sleep quality are increasingly becoming more important.

In 2011, approximately $39 \%$ of Americans, $72 \%$ of whom were adolescents, used mobile phones immediately before sleeping [12]. With the increasing use of mobile technology, mobile health (mHealth) is increasingly being used as a practical intervention tool in medicine and public health [13-19]. The term mHealth refers to the provision of health care services and delivery of personal health information using mobile technology such as mobile phones [20]. The portability of mobile devices used in mHealth addresses issues related to accessibility. This allows health care practitioners to provide services to patients regardless of geographical location [15,21]. Specifically, mHealth technology has additional unique functions that are not typically found in traditional care, such as text messaging-tailored medical advice or individualized phone alarms to encourage specific health behaviors (eg, exercising or taking medications) [22]. Regarding sleep, accelerometers in mobile phones can be used to measure and to evaluate sleep patterns [23], and voice recordings can detect abnormal sleep behavior such as snoring and sleep talking [24].

The potential and importance of mHealth technology in health care and health interventions are evident through more than 100,000 health apps in the app store, and a US \$26 billion estimated mHealth market size in 2017 [25]. The 2016 mHealth App Developer Economics report [26] indicated that 53\% of new apps were designed to improve or address various health conditions. In sum, mHealth is expected to play a significant role in health care due to its ability to be easily integrated into health care services and intervention studies.

\section{Research Objective}

Although new mHealth technologies are assumed to be able to improve the quality and quantity of sleep, limited examinations of behavioral sleep interventions using mobile phones exist $[13,22]$. For example, previous studies [27-31] have focused on examining the technological aspects of mobile phones only (ie, calibration and validation studies, device feasibility). Moreover, previous studies examining the use of the mobile phone's effectiveness for addressing sleep quality or quantity have only focused on one specific sleep disorder, such as sleep disturbance [32] or obstructive sleep apnea [33,34]. Therefore, the primary purpose of this review was to determine the effectiveness for sleep disorder improvement. We hypothesized that interventions with mobile technology have a positive impact on improving sleep quality and various sleep disorders (eg, sleep apnea, snoring, or insomnia).

\section{Methods}

\section{Study Selection Criteria}

This study included articles if they met the following criteria:

1. Study design: randomized controlled trials (RCTs), pre-post studies, and case-control studies;
2. Sleep intervention study: using mHealth technology (eg, a mobile device or app);

3. Intervention outcome: sleep outcome measurement (eg, Insomnia Severity Index [ISI], Pittsburgh Sleep Quality Index [PSQI], or Epworth Sleepiness Scale [ESS]);

4. Language: written in English; and

5. Article type: peer-reviewed publications.

\section{Search Strategy}

Articles published between January 1983 (the year of the first handheld and commercial cellular phone from Motorola [35]) and December 2016 were searched from four electronic databases, including EBSCOhost: Academic Search Complete (ASC) \& Cumulative Index to Nursing and Allied Health Literature (CINAHL), PubMed/Medline, Scopus, and Web of Science. The journal search process occurred from February 18 to 19,2017 . To identify components of three research topics, namely, "sleep," "mHealth," and "study design," the specified search keywords were used as a search algorithm (see Multimedia Appendix 1).

After searching the electronic databases, one author (JCS) selected articles that were published in peer-reviewed journals and excluded books, case reports, conference proceedings, product reviews, newspapers, patents, serials, and theses. Secondly, the same author removed duplicate articles from the combined search results and screened articles based on the title and abstract. In addition, JCS hand-searched for relevant articles in the JMIR search engine on February 28, 2017. Once all full-text articles were found, two researchers (JCS and JK) reviewed each article using the eligibility criteria and eliminated unrelated articles. The entire procedure followed the guidelines for Preferred Reporting Items for Systematic Reviews and Meta-Analysis (PRISMA) [36].

\section{Data Extraction}

The following information was extracted from each article included in the systematic review: first author's name, publication year, the country where the study was conducted, sample size, sample age, sample characteristics, study period, retention rate, study design, the technology used in the intervention, and measurement of sleep outcome. The retention rate was calculated using the number of participants who completed all assessments for the intervention study divided by the number of individuals who were originally recruited. Intervention technology was identified using two approaches: (1) intervention using mobile phone app and (2) supplementary mobile phone usage with traditional intervention. Additional information was extracted by using the empirical approach of statistical analysis such as effect size, standard error, and standard deviation for the difference before and after interventions.

\section{Statistical Analysis}

The effect size and standard deviation for each study's sleep outcome measurement were obtained from data extraction. With each effect size, there was a difference of calculation for the total effect size based on the type of study. For example, the effect size of pre-post test was only considered the difference between pretest scores and posttest scores. On the other hand, 
the effect size of RCTs was calculated using the difference between the intervention and the control groups' effect sizes. Based on the total effect size, sample size, and standard error, two-sample $t$ tests were performed to determine the mobile phone intervention effectiveness.

\section{Study Quality Assessment}

The study quality assessment tool was derived from Zhu and An [37], and then revised after discussion and peer review by the researchers for the purpose of this study. The quality of research was assessed using the following criteria: (1) the research question and objectives were stated clearly, (2) mobile health and/or mHealth was defined, (3) a control group was included, (4) participants were randomly recruited from a well-defined population, (5) sample size was more than 30, (6) attrition was analyzed and determined not to significantly differ by respondents' baseline characteristics between control and experiment groups $(<20 \%)$, (7) baseline characteristics between control and intervention groups were similar, (8) the intervention period was at least 4 weeks, (9) the sleep disorder measurement tools were shown to be reliable and valid in previous studies, and (10) demographic information was available to control for potential confounders in future analysis. A sample size of 30 was chosen due to a guarantee of a normal sample distribution based on the central limit theorem. The total study quality score was determined by summing items 1 to 10 , and categories were created to define a general quality of research as poor (score 0-3); moderate (score 4-6), and high (score 7-10).

\section{Results}

\section{Study Selection}

The results of the literature search are summarized in Figure 1. A total of 2674 articles were initially selected from four electronic databases (EBSCOhost: CINAHL\&ASC, PubMed/ Medline, Scopus, and Web of Science). After excluding 440 duplicate articles, 896 articles were excluded from the first screening of peer-reviewed journal articles and 1339 articles were left. After the first screening, five articles were included from hand searching, and 1304 were excluded based on the title $(n=1180)$ and abstract $(n=124)$. All 39 remaining articles were then downloaded as PDF files for full-text peer review and discussion [13-16,21,22,38-70]. We excluded 23 articles after the full-text screening for the following reasons: (1) a device or program feasibility study $(n=2)[66,69],(2)$ duplicated article $(\mathrm{n}=1)$ [21], (3) not an intervention study $(\mathrm{n}=5)$ ) [39,43,47,49,53], (4) not a mobile phone intervention $(\mathrm{n}=7)$ $[14,42,48,56,58,63,68],(5)$ no sleep outcome $(n=3)[16,44,65]$, and (6) a protocol or trial $(n=5)[40,45,50-52]$. The entire selection procedure was independently performed by two researchers (JCS and JK), and then the research team resolved differences by discussion. From individual selections, the interrater reliability analysis using the kappa statistic was performed with peer reviewers to determine consistency among raters. The interrater reliability was found to be Cohen kappa $=.80$, representing substantial agreement [20]. Therefore, a total of 16 articles that satisfied the inclusion criteria were used for the final analysis.

\section{Study Characteristics}

Table 1 provides summary information of individual studies. A total of 16 studies were included in the analysis: one case study [46], three pre-post studies [13,15,41], and 11 RCTs $[21,22,38,54,55,57,59,61,62,64,67,70]$. Of the 12 RCTs, three studies $[62,64,67]$ used mobile phone apps as an intervention tool; one study [21] used text messages as part of the intervention. RCTs ranged in total sample size from 30 to 502 and had a larger sample size than pre-post studies, which ranged from three [13] to 12 [41]. The study period for RCTs was from 4 weeks to 6 months, whereas for pre-post studies it was between 2 and 5 weeks. For the study region, eight studies were performed in the Unites States [13,15,21,41,55,61,62,70], two studies in Canada [54,67], two studies in Asia (Hong Kong [57] and Taiwan [46]), and four studies in Europe (Finland [38], France [64], Netherlands [21], and Sweden [59]). Most of the studies were published after 2012, except one study that was published in 2006 [67]. Three studies [15,46,64] focused on an elderly population, whereas three studies $[21,67,70]$ focused on a young adult population. 
Figure 1. Study selection procedure according to the PRISMA guidelines.

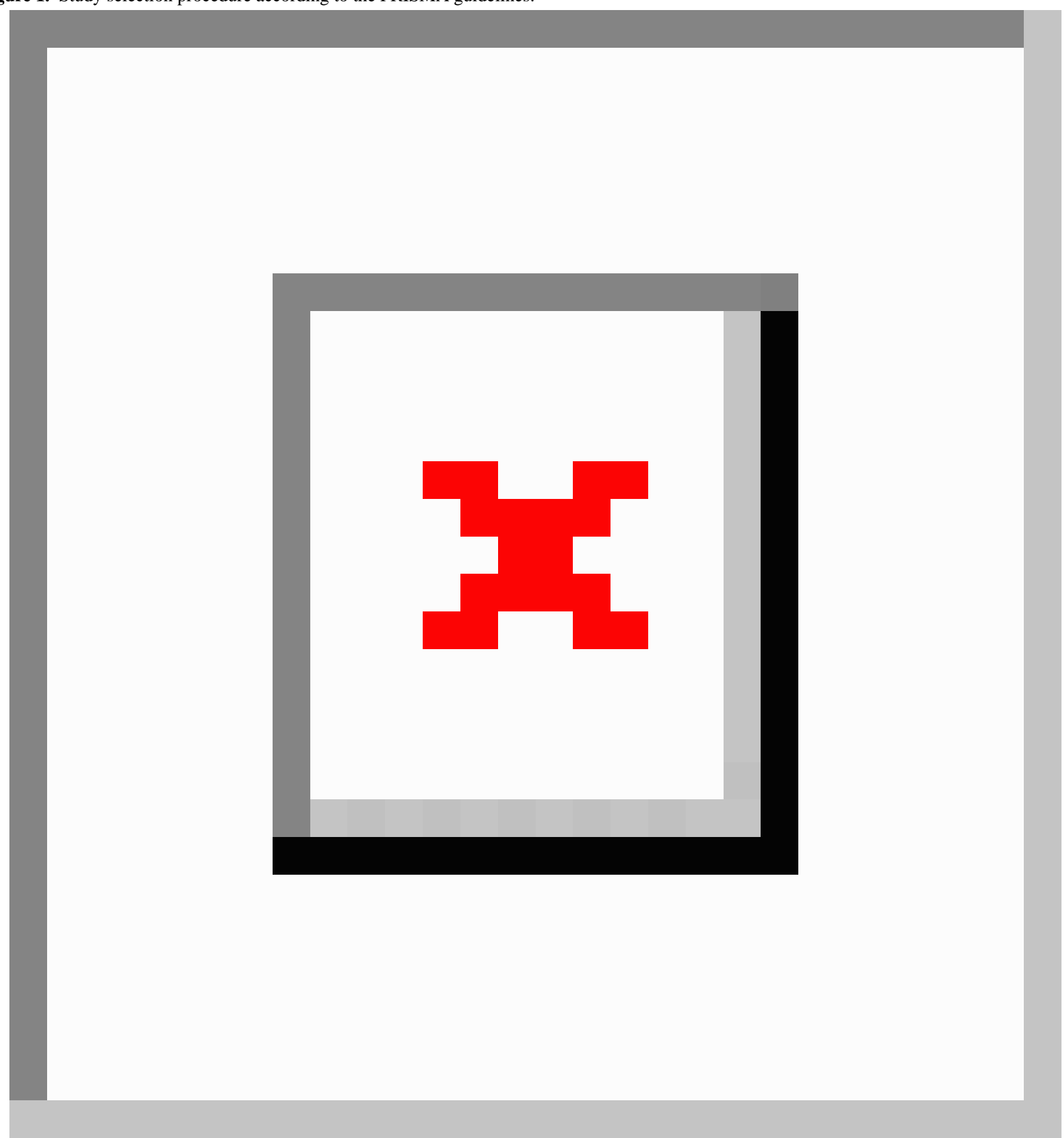


Table 1. Basic characteristics of the studies of mobile phone interventions on sleep disorders $(\mathrm{N}=16)$.

\begin{tabular}{|c|c|c|c|c|c|c|c|c|}
\hline Author(s), Year & $\begin{array}{l}\text { Study } \\
\text { region }\end{array}$ & $\begin{array}{l}\text { Sample } \\
\text { characteristics }^{\mathrm{a}}\end{array}$ & $\begin{array}{l}\text { Sample } \\
\text { size }\end{array}$ & $\begin{array}{l}\text { Mean } \\
\text { age }\end{array}$ & $\begin{array}{l}\text { Study } \\
\text { period }\end{array}$ & $\begin{array}{l}\text { Intervention } \\
\text { methods }^{\mathrm{b}}\end{array}$ & $\begin{array}{l}\text { Study } \\
\text { design }^{c}\end{array}$ & $\begin{array}{l}\text { Sleep outcome } \\
\text { measurement }^{\mathrm{d}}\end{array}$ \\
\hline Anttalainen el al, 2014 [38] & Finland & OSA patients & 111 & 55.27 & $3 \mathrm{~m}$ & Phone + CPAP & RCT & AHI, ESS \\
\hline Babson et al, 2015 [13] & $\begin{array}{l}\text { United } \\
\text { States }\end{array}$ & $\begin{array}{l}\text { Veterans with } \\
\text { CUD }\end{array}$ & 3 & 47 & $2 w$ & $\begin{array}{l}\text { App: “CBT-I } \\
\text { Coach" for iOS }\end{array}$ & Pre-post & PSQI \\
\hline Bauer et al, 2012 [41] & $\begin{array}{l}\text { United } \\
\text { States }\end{array}$ & $\begin{array}{l}\text { Metropolitan area } \\
\text { adults }\end{array}$ & 12 & 32 & $4 \mathrm{w}$ & $\begin{array}{l}\text { App: "ShutEye" } \\
\text { for Android }\end{array}$ & Pre-post & ESS \\
\hline Chen et al, 2015 [46] & Taiwan & Elderly female & 1 & 64 & $5 \mathrm{w}$ & $\begin{array}{l}\text { App: "Win-Win } \\
\text { A Sleep" }\end{array}$ & $\begin{array}{l}\text { Case } \\
\text { study }\end{array}$ & SSR \\
\hline Filion et al, 2015 [21] & $\begin{array}{l}\text { United } \\
\text { States }\end{array}$ & $\begin{array}{l}\text { Young adult } \\
\text { smokers }\end{array}$ & 116 & $18-25$ & $6 \mathrm{w}$ & Text message & $\mathrm{RCT}$ & SQ_PSQI, TST \\
\hline Fox el al, 2012 [54] & Canada & OSA patients & 75 & 53.54 & $3 \mathrm{~m}$ & Phone + CPAP & RCT & AHI, ESS \\
\hline Freeman et al, 2015 [55] & $\begin{array}{l}\text { United } \\
\text { States }\end{array}$ & $\begin{array}{l}\text { Breast cancer } \\
\text { survivors }\end{array}$ & 102 & 55.44 & $3 \mathrm{~m}$ & $\begin{array}{l}\text { Phone-supported } \\
\text { teleconference }\end{array}$ & $\mathrm{RCT}$ & PSQI \\
\hline Ho et al, 2014 [57] & Hong Kong & Insomnia patients & 149 & 38.5 & $12 \mathrm{w}$ & Phone + CBT-I & $\mathrm{RCT}$ & $\begin{array}{l}\text { PSQI, ISI, } \\
\text { DBAS, SE, SQ, } \\
\text { SOL, WASO, } \\
\text { TST }\end{array}$ \\
\hline Jernelov et al, 2012 [59] & Sweden & $\begin{array}{l}\text { Adults with in- } \\
\text { somnia }\end{array}$ & 133 & 47.9 & $6 \mathrm{w}$ & $\begin{array}{l}\text { Phone + biblio- } \\
\text { therapy }\end{array}$ & RCT & $\begin{array}{l}\text { ISI, DBAS, SE, } \\
\text { SQ, SOL, WA- } \\
\text { SO, TST, BTS, } \\
\text { SRBQ }\end{array}$ \\
\hline Koffel et al, 2016 [62] & $\begin{array}{l}\text { United } \\
\text { States }\end{array}$ & Veterans & 18 & 48.5 & $5 \mathrm{w}$ & $\begin{array}{l}\text { Apps: "CBT-I } \\
\text { Coach" }\end{array}$ & RCT & ISI \\
\hline Lichstein et al, 2013 [15] & $\begin{array}{l}\text { United } \\
\text { States }\end{array}$ & $\begin{array}{l}\text { Rural area adults } \\
\text { with insomnia }\end{array}$ & 5 & 65.8 & $5 \mathrm{w}$ & $\begin{array}{l}\text { Apps: "Skype" + } \\
\text { CBT }\end{array}$ & Pre-post & $\begin{array}{l}\text { ISI, HRDS, } \\
\text { NWAK, SOL, } \\
\text { SQ, WASO }\end{array}$ \\
\hline Kauffman 2016 [61] & $\begin{array}{l}\text { United } \\
\text { States }\end{array}$ & $\begin{array}{l}\text { Menopausal sta- } \\
\text { tus with insomnia }\end{array}$ & 106 & 54.85 & $24 \mathrm{w}$ & Phone + CBT-I & RCT & $\begin{array}{l}\text { ISI, PSQI, SE, } \\
\text { SOL, TST, WA- } \\
\text { SO }\end{array}$ \\
\hline Mendelson et al, 2014 [64] & France & OSA patients & 107 & 63 & $4 \mathrm{w}$ & $\begin{array}{l}\text { Researcher-built } \\
\text { app + CPAP }\end{array}$ & $\mathrm{RCT}$ & ESS \\
\hline Stremler et al, 2006 [67] & Canada & $\begin{array}{l}\text { First-time moth- } \\
\text { ers }\end{array}$ & 30 & 31.85 & $6 \mathrm{w}$ & $\begin{array}{l}\text { Phone + sleep ed- } \\
\text { ucation }\end{array}$ & RCT & GSDS \\
\hline van Dron-gelen et al, 2014 [22] & Netherlands & Airline pilots & 502 & 40.9 & $6 \mathrm{~m}$ & $\begin{array}{l}\text { App: "More ener- } \\
\text { gy" }\end{array}$ & $\mathrm{RCT}$ & PSQI \\
\hline Vuletic el al., 2016 [70] & $\begin{array}{l}\text { United } \\
\text { States }\end{array}$ & $\begin{array}{l}\text { Soldiers With } \\
\text { MTBI }\end{array}$ & 356 & 29.35 & $6 \mathrm{~m}$ & $\begin{array}{l}\text { Telephone-based } \\
\text { problem-solving } \\
\text { treatment }\end{array}$ & RCT & $\begin{array}{l}\text { PSQI, SE, SOL, } \\
\text { SQ }\end{array}$ \\
\hline
\end{tabular}

${ }^{a}$ CUD: cannabis use disorders; MTBI: mild traumatic brain injury; OSA: obstructive sleep apnea.

${ }^{\mathrm{b}}$ CBT-I: Cognitive Behavioral Therapy for Insomnia; CPAP: continuous positive airway pressure.

${ }^{\mathrm{c}} \mathrm{RCT}$ : randomized controlled trial.

${ }^{d}$ AHI: Apnea-Hypopnea Index; BTS: bed time stress; DBAS: Dysfunctional Beliefs and Attitudes about Sleep scale; ESS: Epworth Sleepiness Scale; GSDS: General Sleep Disturbance Scale; HRSD: Hamilton Rating Scale for Depression with sleep; ISI: Insomnia Severity Index; PSQI: Pittsburgh Sleep Quality Index; NWAK: number of awakenings; SE: sleep efficiency; SOL: sleep-onset latency; SQ: sleep quality; SQ_PSQI: extracted sleep quality score based on PSQI; SRBQ: Sleep-Related Behavior Questionnaire; SSR: Sleep Satisfaction Rate; TST: total sleep time; WASO: wakefulness after sleep onset. 
Table 2. Summary of sleep measurement tools and study design for mobile phone sleep intervention included in the systematic review (N=16).

\begin{tabular}{|c|c|c|c|c|c|}
\hline Measurement & Scales & $\begin{array}{l}\text { Case study } \\
\& \text { pre-post } \\
\text { test }(n=4)\end{array}$ & $\begin{array}{l}\text { RCT }(\mathrm{n}=12) \\
\text { Standard treatment: } \\
\text { CBT-I \& CPAP } \\
(\mathrm{n}=5)^{\mathrm{a}}\end{array}$ & $\begin{array}{l}\text { Other recognized } \\
\text { treatment }(\mathrm{n}=7)\end{array}$ & $\begin{array}{l}\text { Waitlist } \\
(\mathrm{n}=4)^{\mathrm{b}}\end{array}$ \\
\hline Apnea-Hypopnea Index (AHI) & Score (total apneas event/TST) & 0 & $2[38,54]$ & 0 & 0 \\
\hline Bed time stress (BTS) & Scored on scale $0-5$ & 0 & 0 & $1[59]$ & $1[59]$ \\
\hline $\begin{array}{l}\text { Dysfunctional Beliefs and Attitudes } \\
\text { about Sleep Scale (DBAS) }\end{array}$ & 30 items with scale $1-10$ (total: 300 ) & 0 & $1[57]$ & $1[59]$ & $2[57,59]$ \\
\hline Epworth Sleepiness Scale (ESS) & 8 items with scale $0-3$ (total: 24 ) & $1[41]$ & $2[38,54]$ & $1[64]$ & 0 \\
\hline $\begin{array}{l}\text { General Sleep Disturbance Scale } \\
\text { (GSDS) }\end{array}$ & 21 items with scale 0-7 (total:147) & 0 & 0 & $1[67]$ & 0 \\
\hline $\begin{array}{l}\text { Hamilton Rating Scale for Depression } \\
\text { with sleep (HRSD) }\end{array}$ & $\begin{array}{l}\text { Total } 21 \text { items: }{ }^{\text {c }:} 10 \text { items with scale } \\
0-4,2 \text { items with scale } 0-3 \text {, and } 10 \\
\text { items with scale } 0-2 \text { (total: } 66 \text { ) }\end{array}$ & $1[15]$ & 0 & 0 & 0 \\
\hline Insomnia Severity Index (ISI) & 7 items with scale $0-4$ (total: 28 ) & $1[15]$ & $3[15,57,61]$ & $2[59,62]$ & $2[57,59]$ \\
\hline Number of awakenings (NWAK) & Frequency of awakening & $1[15]$ & 0 & 0 & 0 \\
\hline $\begin{array}{l}\text { Pittsburgh Sleep Quality Index } \\
\text { (PSQI) }\end{array}$ & $\begin{array}{l}7 \text { components calculated from } 9 \\
\text { questions with scale } 0-3 \text { (total: } 21 \text { ) }\end{array}$ & $1[13]$ & $2[57,61]$ & $2[55,70]$ & $3[22,55,57]$ \\
\hline Sleep efficiency $(\mathrm{SE})^{\mathrm{c}}$ & Percentage (TST/total time in bed) & 0 & $2[57,61]$ & $2[59,70]$ & $2[57,59]$ \\
\hline Sleep-onset latency (SOL) & Minutes & $1[15]$ & $2[57,61]$ & $2[59,70]$ & $2[57,59]$ \\
\hline Sleep quality $(\mathrm{SQ})^{\mathrm{c}}$ & Scored on scale $1-5$ & $1[15]$ & $1[57]$ & $2[59,70]$ & $2[57,59]$ \\
\hline $\begin{array}{l}\text { Extracted sleep quality score based } \\
\text { on PSQI (SQ_PSQI) }\end{array}$ & 8 items with scale 1-4 (total: 32 ) & 0 & 0 & $1[21]$ & $1[21]$ \\
\hline $\begin{array}{l}\text { Sleep-Related Behavior Questionnaire } \\
\text { (SRBQ) }\end{array}$ & 32 items with scale 1-5 (total: 160 ) & 0 & 0 & $1[59]$ & $1[59]$ \\
\hline Sleep Satisfaction Rate $(\mathrm{SSR})^{\mathrm{c}}$ & Scored on scale $0-3$ & $1[46]$ & 0 & 0 & 0 \\
\hline Total sleep time (TST) & Hours & 0 & $2[57,61]$ & $2[21,59]$ & $3[21,57,59]$ \\
\hline $\begin{array}{l}\text { Wakefulness after initial sleep onset } \\
\text { (WASO) }\end{array}$ & Minutes & $1[15]$ & $2[57,61]$ & $1[59]$ & $2[57,59]$ \\
\hline
\end{tabular}

${ }^{\mathrm{a} C B T}$-I: Cognitive Behavioral Therapy for Insomnia; CPAP: continuous positive airway pressure.

${ }^{b}$ Three articles have two comparison groups (waitlist vs other).

${ }^{\mathrm{c}}$ Higher scores indicate lesser severity.

Table 2 shows the number of studies based on study design and sleep measurement tools. Several questionnaires were used to evaluate various aspects of sleep quality and quantity.

Specifically, the Pittsburgh Sleep Quality Index (PSQI) $[13,21,22,55,57,61,70]$ had a list of items to evaluate sleep quality and it was the most frequently used measure in our review. In addition, three studies used a sleep quality [15,57,59] measure that consisted of a simple question about the participant's perception about sleep quality using a five-point scale. Moreover, five studies $[15,21,57,59,61]$ used measures of sleep quantity: (1) sleep-onset latency $(n=4$; the length of time to transition from full wakefulness to sleep completely) $[15,57,59,61],(2)$ number of awakenings $(n=1$, the frequency of awakening during sleep) [15], (3) wake after sleep onset $(n=4$; the amount of time [eg, minutes] one wakes up during sleep) $[15,57,59,61]$, and (4) total sleep time $(n=4$; total length of sleep time) $[21,57,59,61]$. Total sleep time is also used to calculate sleep efficiency $[57,59,61]$; that is, the percentage of total sleep time per total bed time. For the measurement of behavioral aspects of sleep, some researchers used the Epworth Sleepiness Scale (ESS) $(n=4) \quad[38,41,54,64]$ to capture participant sleepiness. Also two additional studies measured other specific sleep-related behaviors, such as the Sleep-Related Behavior Questionnaire (SRBQ) [59], the Dysfunctional Beliefs and Attitudes about Sleep Scale (DBAS) [57,59], and Sleep Satisfaction Rate (SSR) [46]. Finally, some sleep measurement tools focused on specific sleep disorders such as the severity of insomnia. The Apnea-Hypopnea Index (AHI) [38,54] is used to evaluate sleep apnea, and the General Sleep Disturbance Scale (GSDS) [67] is meant to examine factors that interrupt sleep. Two studies $[15,59]$ used tools to examine the emotional aspects of sleep, such as bed time stress (BTS) levels [59], and the Hamilton Rating Scale for Depression with sleep (HRSD) [15]. All sleep outcome measurements were conducted by subjective measurement (ie, self-report questionnaire). 
Table 3. Summary statistics: quality assessment of each journal and the effects of intervention through $t$ test by intervention type and sleep outcome measurement.

\begin{tabular}{|c|c|c|c|c|c|c|}
\hline Author(s), year & $\begin{array}{l}\text { Quality } \\
\text { score }\end{array}$ & Study design: intervention type ${ }^{\mathrm{a}}$ & $\begin{array}{l}\text { Sleep } \\
\text { measurement }^{\mathrm{b}}\end{array}$ & $\begin{array}{l}\text { Effect size, } \\
\text { mean }(\mathrm{SD})\end{array}$ & $95 \% \mathrm{CI}$ & $P$ \\
\hline \multirow{2}{*}{ Anttalainen el al, 2014 [38] } & 7 & RCT: mobile + CPAP vs standard CPAP & AHI & $-1.9(2.9)$ & $-2.4,-1.4$ & $<.001$ \\
\hline & & & ESS & $0.0(1.7)$ & $-0.3,0.3$ & $>.99$ \\
\hline Babson et al, 2015 [13] & 3 & Pre-post & PSQI & $-1.5(2.4)$ & $-6.2,3.2$ & NA \\
\hline Bauer et al, 2012 [41] & 5 & Pre-post & ESS & $-1.7(1.3)$ & $-2.4,-0.9$ & .001 \\
\hline Chen et al, 2015 [46] & 2 & Case study & SSR & & & NA \\
\hline \multirow[t]{3}{*}{ Filion et al, 2015 [21] } & 8 & $\begin{array}{l}\text { RCT: smoking prevention text vs sleep or } \\
\text { activity }\end{array}$ & SQ_PSQI & $-0.2(1.7)$ & $-0.5,0.1$ & .14 \\
\hline & & & TST (weekday) & $0.6(0.5)$ & $0.5,0.6$ & $<.001$ \\
\hline & & Promotion text & TST (weekend) & $0.6(0.7)$ & $0.5,0.7$ & $<.001$ \\
\hline \multirow[t]{2}{*}{ Fox el al, 2012 [54] } & 8 & RCT: mobile + CPAP vs standard CPAP & AHI & $-1.9(4.3)$ & $-2.9,-0.9$ & $<.001$ \\
\hline & & & ESS & $-0.9(5.1)$ & $-2.1,0.3$ & .13 \\
\hline \multirow[t]{2}{*}{ Freeman et al, 2015 [55] } & 9 & RCT: mobile vs waitlist & PSQI & $-2.6(1.5)$ & $-2.9,-2.2$ & $<.001$ \\
\hline & & RCT: mobile vs standard treatment & PSQI & $-0.7(1.4)$ & $-1.0,-0.4$ & $<.001$ \\
\hline \multirow[t]{16}{*}{ Ho et al, 2014 [57] } & 8 & RCT: mobile + CBT-I vs waitlist & DBAS & $-23.5(15.1)$ & $-25.5,-21.5$ & $<.001$ \\
\hline & & & ISI & $-3.1(1.8)$ & $-3.3,-2.9$ & $<.001$ \\
\hline & & & PSQI & $-2.3(1.5)$ & $-2.5,-2.1$ & $<.001$ \\
\hline & & & SE & $4.5(4.8)$ & $3.8,5.2$ & $<.001$ \\
\hline & & & SOL & $-7.4(12.9)$ & $-9.2,-5.6$ & $<.001$ \\
\hline & & & SQ & $-0.2(0.2)$ & $-0.2,-0.2$ & $<.001$ \\
\hline & & & TST & $0.0(8.8)$ & $-1.2,1.2$ & .99 \\
\hline & & & WASO & $-10.8(14.8)$ & $-12.8,-8.8$ & $<.001$ \\
\hline & & RCT: mobile + CBT-I vs standard CBT-I & DBAS & $-0.3(16.0)$ & $-2.5,1.9$ & $<.001$ \\
\hline & & & ISI & $-1.1(1.8)$ & $-1.3,-0.9$ & $<.001$ \\
\hline & & & PSQI & $-0.8(1.5)$ & $-1.0,-0.6$ & $<.001$ \\
\hline & & & SE & $1.2(4.8)$ & $0.5,1.9$ & $<.001$ \\
\hline & & & SOL & $-7.1(12.9)$ & $-8.9,-5.3$ & $<.001$ \\
\hline & & & SQ & $-0.1(0.2)$ & $-0.1,-0.1$ & $<.001$ \\
\hline & & & $\mathrm{TST}$ & $-0.1(8.8)$ & $-1.3,1.1$ & .74 \\
\hline & & & WASO & $-7.7(14.7)$ & $-9.7,-5.7$ & $<.001$ \\
\hline \multirow[t]{11}{*}{ Jernelov et al, 2012 [59] } & 9 & RCT: mobile + bibliotherapy vs waitlist & BTS & $-0.9(0.4)$ & $-1.0,-0.8$ & $<.001$ \\
\hline & & & DBAS & $-56.4(9.8)$ & $-58.4,-54.4$ & $<.001$ \\
\hline & & & ISI & $-8.8(1.6)$ & $-9.1,-8.5$ & $<.001$ \\
\hline & & & SE & $15.3(7.1)$ & $13.8,16.8$ & $<.001$ \\
\hline & & & SOL & $-30.7(20.4)$ & $-35.0,-26.4$ & $<.001$ \\
\hline & & & SQ & $0.9(0.2)$ & $0.9,0.9$ & $<.001$ \\
\hline & & & SRBQ & $-21.9(4.8)$ & $-22.9,-20.9$ & $<.001$ \\
\hline & & & $\mathrm{TST}$ & $0.4(0.5)$ & $0.3,0.5$ & $<.001$ \\
\hline & & & WASO & $-30.1(18.9)$ & $-34.1,-26.1$ & $<.001$ \\
\hline & & $\begin{array}{l}\text { RCT: mobile+ bibliotherapy vs bibliother- } \\
\text { apy only }\end{array}$ & BTS & $-0.9(0.4)$ & $-1.0,-0.8$ & $<.001$ \\
\hline & & & DBAS & $-37.0(11.0)$ & $-39.3,-34.7$ & $<.001$ \\
\hline
\end{tabular}




\begin{tabular}{|c|c|c|c|c|c|c|}
\hline Author(s), year & $\begin{array}{l}\text { Quality } \\
\text { score }\end{array}$ & Study design: intervention type ${ }^{\mathrm{a}}$ & $\begin{array}{l}\text { Sleep } \\
\text { measurement }^{\mathrm{b}}\end{array}$ & $\begin{array}{l}\text { Effect size, } \\
\text { mean (SD) }\end{array}$ & $95 \% \mathrm{CI}$ & $P$ \\
\hline & & & ISI & $-4.5(1.5)$ & $-4.8,-4.2$ & $<.001$ \\
\hline & & & SE & $10.2(7.0)$ & $8.7,11.7$ & $<.001$ \\
\hline & & & SOL & $-14.8(21.8)$ & $-19.3,-10.3$ & $<.001$ \\
\hline & & & SQ & $0.5(0.2)$ & $0.5,0.5$ & $<.001$ \\
\hline & & & SRBQ & $-15.3(5.4)$ & $-16.4,-14.2$ & $<.001$ \\
\hline & & & TST & $0.0(0.5)$ & $-0.1,0.1$ & .69 \\
\hline & & & WASO & $-21.1(19.4)$ & $-25.1,-17.1$ & $<.001$ \\
\hline Koffel et al, 2016 [62] & 8 & RCT: app use vs non app & ISI & $3.4(4.6)$ & $1.2,5.5$ & .008 \\
\hline \multirow[t]{6}{*}{ Lichstein et al, 2013 [15] } & 6 & Pre-post & HRSD & $-7.0(3.6)$ & $-10.2,-3.8$ & .01 \\
\hline & & & ISI & $-11.3(3.3)$ & $-14.2,-8.3$ & .002 \\
\hline & & & NWAK & $-1.7(2.1)$ & $-3.5,0.1$ & .14 \\
\hline & & & SOL & $-18.4(20.9)$ & $-36.7,-0.1$ & .12 \\
\hline & & & SQ & $0.5(0.1)$ & $0.4,0.6$ & .001 \\
\hline & & & WASO & $-23.8(9.2)$ & $-31.9,-15.7$ & .004 \\
\hline \multirow[t]{6}{*}{ Kauffman 2016 [61] } & 8 & $\begin{array}{l}\text { RCT: mobile + CBT-I vs menopause edu- } \\
\text { cation }\end{array}$ & ISI & $-4.0(5.6)$ & $-5.1,-2.9$ & $<.001$ \\
\hline & & & PSQI & $-1.6(3.0)$ & $-2.2,-1.0$ & $<.001$ \\
\hline & & & SE & $3.2(12.3)$ & $0.8,5.6$ & .009 \\
\hline & & & SOL & $-11.9(36.3)$ & $-18.8,-5.0$ & .001 \\
\hline & & & TST & $0.2(1.2)$ & $0.0,0.4$ & .08 \\
\hline & & & WASO & $-6.8(47.3)$ & $-15.8,2.2$ & .14 \\
\hline Mendelson et al, 2014 [64] & 8 & RCT: app + CPAP vs standard CPAP & ESS & $-0.2(1.5)$ & $-0.5,0.1$ & .17 \\
\hline Stremler et al, 2006 [67] & 8 & RCT: mobile + education vs education & GSDS & $-13.3(8.2)$ & $-16.2,-10.4$ & $<.001$ \\
\hline van Drongelen et al, 2014 [22] & 9 & RCT: app use vs non app & PSQI & $-0.6(1.3)$ & $-0.7,-0.4$ & $<.001$ \\
\hline Vuletic el al, 2016 [70] & 8 & RCT: mobile + education vs education & PSQI & $-1.5(1.5)$ & $-1.7,-1.4$ & $<.001$ \\
\hline
\end{tabular}

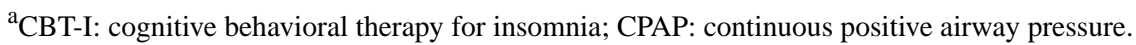

${ }^{b}$ AHI: Apnea-Hypopnea Index; BTS: bed time stress; DBAS: Dysfunctional Beliefs and Attitudes about Sleep Scale; ESS: Epworth Sleepiness Scale; GSDS: General Sleep Disturbance Scale; HRSD: Hamilton Rating Scale for Depression with sleep; ISI: Insomnia Severity Index; PSQI: Pittsburgh Sleep Quality Index; NWAK: number of awakenings; SE: sleep efficiency; SOL: sleep-onset latency; SQ: sleep quality; SQ_PSQI: extracted sleep quality score based on PSQI; SRBQ: Sleep-Related Behavior Questionnaire; SSR: Sleep Satisfaction Rate; TST: total sleep time; WASO: wakefulness after initial sleep onset.

Table 3 provides a summary of the effectiveness of each sleep intervention. It is categorized by sleep outcome measurement, and the statistics can be comparable if there are more than two sleep measures. Specifically, half of studies $[13,22,41,46,62,64,67,70]$ used a single sleep outcome measurement, while others had at least two or more measurements. Of nine studies [13,15,38,46,54,57,61,62,64] of standard treatment, five studies compared a mobile phone intervention and standard treatment intervention: (1) continuous positive airway pressure (CPAP) [38,54,64] and (2) cognitive behavioral therapy for insomnia (CBT-I) [57,61]. Five studies $[13,22,41,46,61]$ focused on a mobile phone app. Two of these studies $[13,61]$ used a "CBT-I coach" app that was developed based on CBT-I, which is considered one of the traditional standard treatments for insomnia (Figure 2). 
Figure 2. Sample size based on the intervention methods $(\mathrm{N}=16)$.

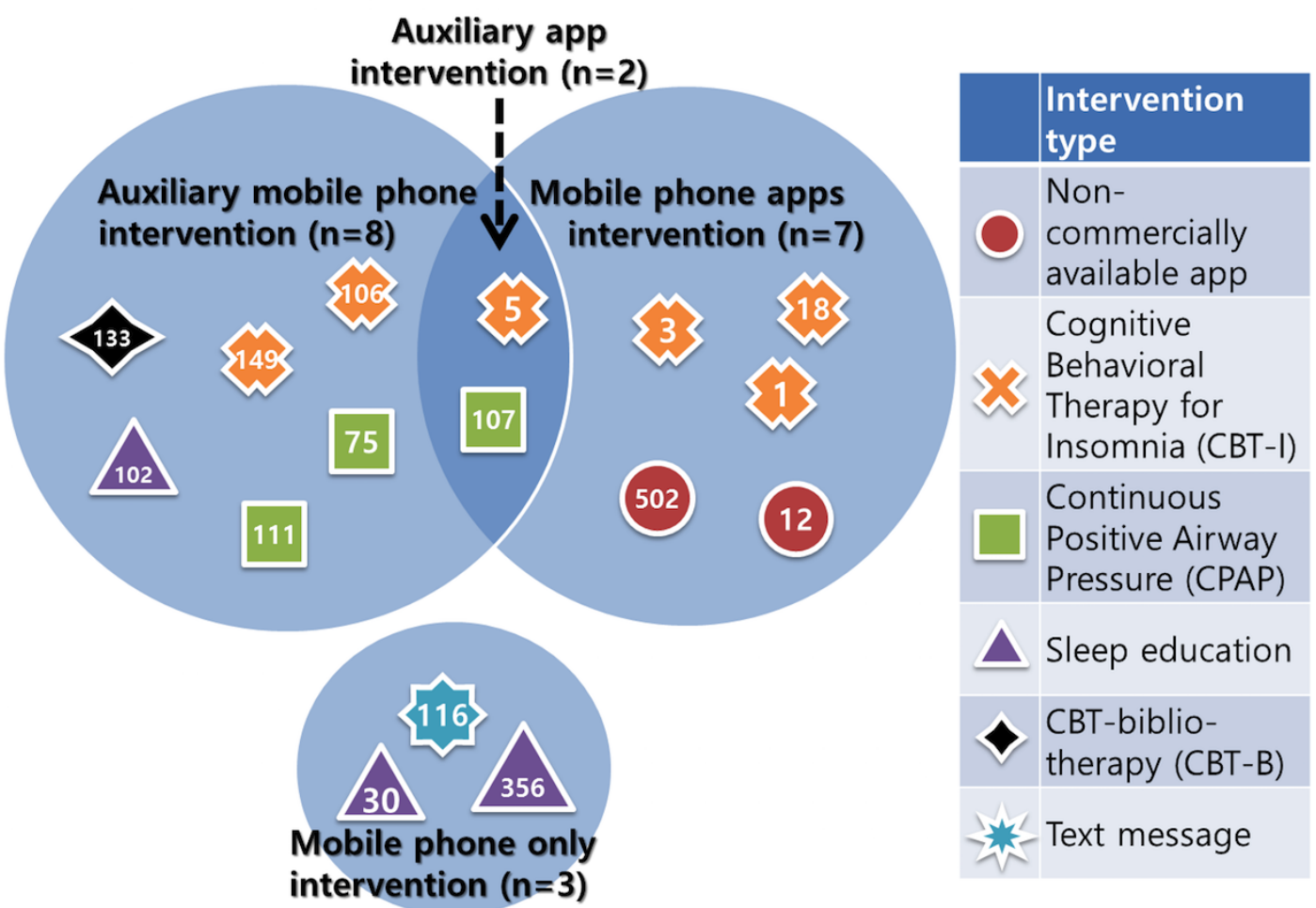

Table 4. Quality assessment of studies to determine the impact of sleep intervention with mobile technology on sleep disorders.

\begin{tabular}{lc}
\hline Criteria item & Score, mean (SD) \\
\hline 1. Research question and objective were stated clearly & $0.94(0.24)$ \\
2. Definition of telehealth and/or mHealth was stated & $0.18(0.39)$ \\
3. A control group was included & $0.82(0.39)$ \\
4. Participants were randomly recruited from well-defined population & $0.82(0.39)$ \\
5. Sample size was >30 & $0.76(0.44)$ \\
6. Attrition was analyzed and determined not to significantly differ by respondents' baseline characteristics between control & $0.47(0.51)$ \\
and experiment groups (<20\%) & $0.76(0.44)$ \\
7. Baseline characteristics between control and intervention groups were similar & $0.94(0.24)$ \\
8. The intervention period was at least 4 weeks & $0.88(0.33)$ \\
9. The sleep disorder measurement tools were shown to be reliable and valid in previously published studies & $0.82(0.39)$ \\
10. Demographic information is available to control potential confounders for future analysis & 7.41 (0.44) \\
Total study quality score ${ }^{\mathrm{a}}$ & \\
\hline
\end{tabular}

${ }^{\mathrm{a}}$ By summing up items 1 to 10 (range 3-10).

\section{Study Quality}

Table 4 summarizes the results of the quality assessment of the studies included in this review. The quality score of the final articles ranged from 3 to 10 out of a possible score of 10 , with an overall mean score of 7.41 (SD 0.44). The distribution of quality scores differed substantially across each criterion. Of 16 articles, 12 articles were considered high quality $[21,22,38,54,55,57,59,61,62,64,67,70]$, two articles moderate quality $[15,41]$, and two articles poor quality $[13,46]$. Most of the studies had clear research questions and objectives
$[13,15,21,22,38,41,46,54,55,57,59,62,64,67,70]$, and used valid sleep measurement tools $[13,15,21,22,38,41,54,55,57,59,61$, $62,64,70]$ for outcome measures after 4 weeks $[15,21,22,38$, $41,46,54,55,57,59,61,62,64,67,70]$. All RCTs [21,22,38,54,55, $57,59,61,62,64,67,70]$ satisfied items 3 (ie, existence of control group) and 5 (ie, sample size greater than 30). The mean intraclass correlation (ICC) between peer reviewers for quality assessment was ICC 0.987 (95\% CI 0.964-0.996, $P<.001$ ). 


\section{Effectiveness of Mobile Phones Usage as a Sleep Intervention Tool}

The mobile phone can be used as a tool to effectively deliver and enhance traditional behavioral interventions due to its portability. We found eight articles that described the advantages of using mobile phones to improve traditional intervention methods for sleep disorders $[38,54,55,57,59,61,67,70]$.

\section{Mobile Phone Usage as Alternative Intervention Tools}

Mobile phones are a tool for intervention studies due to the portability for the participant. Within the results of our review, two studies focused on the effectiveness of mobile phones as intervention tools.

Stremler et al [67] was the first published research article that used a mobile phone as a behavioral-educational strategy tool for a sleep intervention. The focus of the study was to evaluate the feasibility, acceptability, and effects of a mobile phone intervention on sleep in the early postpartum period. During the 6-week intervention period, the intervention group was provided a well-established booklet, in-depth counseling, and a nurse to call for sleep advice, whereas the control group was only provided a one-page pamphlet and brief meeting session. Because the primary target subjects were first-time mothers and their children, researchers used GSDS to evaluate the sleep disturbances in employed women. As a result, the sleep intervention group had lower GSDS scores as much as 13.3 points compared to the control group $\left(t_{28}=-8.84, P<.001\right)$.

Similarly, Vuletic et al [70] had two intervention groups: (1) a group with 12 biweekly "telecounseling" and (2) an "education-only" group with an educational brochure. The research team developed the telephone-based problem-solving treatment, which was a sleep intervention that related to sleep quality to improve post-deployment soldier's traumatic brain injury. Since the researchers used various sleep outcome measurements such as SOL, total sleep time, sleep disturbance, and daytime dysfunction that were part of PSQI, only PSQI was included for data analysis. After 6 months of intervention, the intervention group with telecounseling had significantly lower scores than the education-only intervention group (effect size $=-1.54$, SE $\left.0.19 ; t_{274}=-16.62, P<.001\right)$.

\section{Mobile Phone Used as Auxiliary Equipment}

Both CPAP and CBT-I are considered standard treatments for obstructive sleep apnea (OSA) [38,54] and sleep disturbances $[13,57,62]$. Three studies $[38,54,61]$ applied mobile phones as supplementary tools in addition to these standard treatments.

Fox and colleagues [54] conducted a RCT to determine the effectiveness and adherence of telemonitoring and CPAP combined. To demonstrate the effectiveness of the intervention, $\mathrm{AHI}$ and ESS were used to measure sleep outcome. Researchers found that participants in the intervention group had an improvement in adherence to CPAP, but no significant differences were found for AHI and ESS between the control and intervention groups. Based on $t$ test results, in addition, the effect size of AHI showed significantly decreased $\left(t_{73}=-3.82\right.$, $P<.001)$.
Anttalainen et al [38] had a similar research method as Fox and colleagues' [54], such as intervention duration, study design, intervention methods, presence of a control group, and sleep outcome measurement. Anttalainen et al did not find a statistically significant difference in ESS between groups, whereas participants in the intervention group had a significantly higher score on the AHI than standard in-person treatment $\left(t_{109}=-6.91, P<.001\right)$. Because ESS between standard CPAP and mobile-supported CPAP were not significantly different, the effects of mobile-supported CPAP did not differ from standard CPAP.

Kauffman [61] conducted a RCT to determine the effectiveness of telephone-based CBT-I to determine the effectiveness of telephone-based CBT-I compared to menopause education control. The target population was menopausal middle-aged women with moderate insomnia (ISI $>15$ ). Based on the $t$ test results, there was a significantly different effect size for the index type sleep measurements between the telephone-based CBT-I and menopause education control (ISI: $t_{104}=-7.33$, $P<.001$; PSQI: $\left.t_{104}=-5.54, P=.007\right)$, whereas sleep time measures were not significant such as sleep onset latency, wake after sleep onset, total sleep time, and sleep efficiency.

\section{Multidimensional Approach to Mobile Phone Usage}

Three studies [55,57,59] examined the effectiveness of mobile phone usage as an alternative intervention tool and as an auxiliary equipment.

Jernelov et al [59] evaluated the effectiveness of mobile phone support with CBT bibliotherapy (CBT). To examine the effectiveness of mobile phone support, a total of 133 participants were randomly allocated to three comparable groups (44 for CBT bibliotherapy with mobile support; 45 for only CBT bibliotherapy; 44 for the control group). After the 6-week intervention, a total of 116 participants completed the follow-up assessment (40 for CBT bibliotherapy with mobile support; 37 for CBT bibliotherapy; 39 for the control group), with an attrition rate of $12.78 \%$. Participants in the mobile-supported CBT bibliotherapy group had significant improvements in all sleep measurements compared to the control group (BTS: $t_{86}=-20.80, P<.001$; DBAS: $t_{86}=-53.96, P<.001$; ISI: $t_{86}=-50.64$, $P<.001$; SE: $t_{85}=20.18, P<.001$; SOL: $t_{85}=-14.06, P<.001$; SQ: $t_{85}=39.59, P<.001$; SRBQ: $t_{86}=-42.81, P<.001$; TST: $t_{85}=6.77$, $P<.001$; WASO: $\left.t_{85}=-14.83, \quad P<.001\right)$, and even CBT bibliotherapy only (BTS: $t_{87}=-21.95, \quad P<.001$; DBAS: $t_{87}=-31.74, P<.001 ;$ ISI: $t_{87}=-28.88, P<.001 ;$ SE: $t_{87}=13.78$, $P<.001$; SOL: $t_{87}=-6.39, P<.001$; SQ: $t_{87}=24.41, P<.001$; SRBQ: $t_{87}=-26.77, P<.001$; WASO: $\left.t_{87}=-10.26, P<.001\right)$, except TST $\left(t_{87}=0.685, P=.84\right)$.

Although Ho et al [57] had a similar study design and approach to Jernelov and colleagues [59], Ho et al had a different intervention tool: the comparison between the self-help CBT-I with the mobile phone support and self-help CBT-I only. Of importance was that this study had a relatively higher attrition rate $(49 \%)$ because this study was community based. To be specific, although the baseline participants were high ( $\mathrm{N}=302$; 103 for CBT-I with mobile support; 104 for CBT-I; 105 for 
control group), the total number of participants that completed the follow-up assessment was similar with other RCTs $(n=149$; 44 for CBT-I with mobile support; 39 for CBT-I; 66 for control group). The intervention had two follow-up sessions (at 4 weeks and at 12 weeks), but the waitlist group did not have 12-week evaluation. Therefore, the statistics in Table 3 were based on the follow-up session at 4 weeks to compare whether both interventions significantly improved the sleep measurement score compared to the initial assessment. From the $t$ test, several sleep outcome measures indicated that mobile phone-supported intervention had a statistically significant improvement compared to the waitlist control group (PSQI: $t_{206}=-21.93$, $P<.001$; ISI: $t_{206}=-24.37, P<.001$; DBAS: $t_{206}=-22.48, P<.001$; SOL: $t_{206}=-8.27, P<.001$; WASO: $t_{206}=-10.56, P<.001$; SE: $t_{206}=13.57, P<.001$; and SQ: $\left.t_{206}=-14.14, P<.001\right)$ and also the standard treatment intervention (PSQI: $t_{205}=-7.63, P<.001$; ISI: $t_{205}=-8.64, \quad P<.001 ; \quad$ SOL: $t_{205}=-7.94, \quad P<.001$; WASO: $t_{205}=-7.53, P<.001 ;$ SE: $t_{205}=3.62, P<.001 ;$ and SQ: $t_{205}=-7.85$, $P<.001)$.

Freedman et al [55] established the "Envision the Rhythms of Life" program, which is a group intervention to increase the quality of life for breast cancer survivors, and also to evaluate its advantages on aspects of quality of life. A total of 118 participants were randomly assigned to three groups (48 participants for the in-person delivery; 23 participants for the mobile phone-supported teleconferencing; 47 participants for waitlists) at the beginning of the study, and 102 participants remained (40 participants for the in-person delivery; 19 participants for the mobile phone-supported teleconferencing; 43 participants for the waitlists) at the end of the study. According to the $t$ test, participants in the mobile phone-supported group had a significant increase in PSQI scores among breast cancer survivors compared to both control groups (standard treatment: mean -0.68 , SD $1.39 ; t_{73}=-4.11, P<.001$; waitlist: mean -2.55 , SD $\left.1.53 ; t_{73}=-13.97, P<.001\right)$. In addition, authors performed the linear multilevel modeling analysis, and found that PSQI was only considerable for group effect $(P<.001)$, not for time $(P=.35)$ or group $\times$ time $(P=.30)$.

\section{Text Message for Sleep Intervention}

Filion et al [21] used a text message-based intervention for young adult smokers to promote better sleep and physical activity habits. A total of 164 baseline participants were assigned to two groups: (1) sleep/physical activity group $(n=63)$ and (2) smoking cessation group $(n=101)$. A total of 129 participants completed the study (smoking cessation group: $n=77$; sleep group: $n=44)$. Participants in the sleep/physical activity group received sleep- and activity-related messages for 6 weeks, whereas the smoking cessation group received quitting smoking-related messages. Although the difference of the PSQI score between the smoking group (mean -1.47 , SD 1.77) and sleep group (mean -1.7 , SD 1.48) was not significant $(P=.60)$, the amount of sleep was significantly different $(P=.03)$. Specifically, the amount of sleep (hours) for the sleep/physical activity group increased (mean 0.52 , SD 0.44 ), whereas sleep among the smoking cessation group decreased (mean -0.03 , SD 0.46).

\section{Effectiveness of Mobile Phone Apps as a Sleep Intervention Tool}

As a measurement tool for sleep disorder intervention, mobile phone apps are able to perform diverse functions (ie, tracking $[13,41,46,62]$, sleep advice for behavioral change $[13,15,41,46]$, and optimized alarms $[13,22,62])$. In our review, seven studies evaluated the effectiveness of these app-based interventions $[13,15,22,41,46,62,64]$.

\section{Mobile Phone Apps as Auxiliary Equipment}

Lichstein et al [15] used the Skype app for teleconferencing in addition to CBT as a sleep intervention. The purpose of the study was to examine the feasibility and effectiveness of interventions to address challenges faced by rural older adults with comorbid conditions, namely insomnia and depression. The researchers demonstrated the limitation of mobile phone apps for older population (age: mean 65.8, SD 10.4 years). From the $t$ test, participants in the Skype group had significant improved sleep quality (sleep quality: $t_{4}=9.7, P<.001$ ), less insomnia (ISI: $t_{4}=-7.54, P=.002$ ), less wakefulness after sleep onset $\left(t_{4}=-5.77, P=.004\right)$, and lower HRSD scores $\left(t_{4}=-4.33\right.$, $P=.01)$. Despite the improvement in sleep quality, this study had a higher attrition rate; only five of 18 baseline participants completed the entire study (Multimedia Appendix 2).

Mendelson et al [64] evaluated whether a combination of the mobile phone app using telemedicine and CPAP had better performance compared to standard care (CPAP only). After 4 weeks of intervention, a total 82 of 107 baseline participants (76.6\%) completed the entire test procedure, and 54 participants adhered to CPAP for more than 4 hours. Although the ESS was statistically significantly different between pretest and posttest (combined intervention: mean -2.3 , SD 4.0, $P<.05$; standard care: mean $-2.1, \mathrm{SD} 4.1, P<.001$ ), the effectiveness of treatment did not differ in each intervention.

\section{Mobile Phone Apps Developed by Researchers to Improve Sleep Behavior}

Bauer et al [41] were the first to assess the use of mobile phone apps for sleep intervention programs. The research team developed the "Shuteye" app in 2011, which offered real-time recommendations to promote awareness related to healthy sleep behaviors. They also highlighted the following as being important for effective sleep apps: design of the app, adherence of mobile phone, appearance, awareness of app usage, and learnability (ie, user-friendly interface). For the intervention study, ESS was measured for 12 participants before and after the intervention. We calculated the changes in participant scores pre- and postintervention based on the raw data provided by the research team. Based on the data in the articles, we performed the paired $t$ test, and ESS decreased after intervention (mean -1.67, SD 1.32; $t_{11}=-4.36, P=.001$ ), although this was not found to be statistically significant, most likely due to the small sample size.

Van Drongelen et al [22] conducted a RCT addressing sleep using a mobile phone app with international aircraft pilots. The "More Energy" app was invented to reduce pilots' fatigue and also to improve their healthy behavior and sleep. During the 6 months of intervention, a total of 390 participants $(77.7 \%$ of 
502 baseline participants: 191 in the intervention group, 199 in waitlists) completed the study. The intervention program showed statistically significant fatigue improvement, and also showed a positive effect on sleep. We calculated the difference between the intervention group (score decreased by mean 0.2, SD 1.2) and waitlists (score increased by mean 0.37, SD 1.32); the PSQI score significantly improved (beta=-0.59, $P=.001$ ).

\section{Mobile Phone Apps With CBT-I}

Three studies $[13,46,62]$ used mobile phone apps to reform CBT-I, which is one of the traditional standard treatments for improving sleep behavior.

Babson et al [13] used a mobile phone app version of CBT-I to determine the feasibility and efficacy for veterans using cannabis to treat sleep disorders. A total of four participants were included in the study (two in the intervention group; two in the control group). According to the $t$ tests result, the mobile phone intervention did not significantly affect the PSQI score $\left(t_{1}=-0.87, P=.48\right)$. However, this study was considered a pre-post study because all participants in the control group dropped out during the test procedure. In addition to the loss of a follow-up evaluation in the control group, several limitations with the study, such as small sample size and the rarity of the target population (ie, veterans using cannabis treatment for sleep disorders), caused the authors' skeptical conclusion of the ineffectiveness of mHealth intervention.

Chen et al [46] used the "Win-Win a Sleep" app, which was developed from CBT-I, and revealed effectiveness and feasibility of sleep interventions. In this case study, a participant who was female aged 63 years suffered from insomnia and used the app during a 5-week test period. Because the participant took hypnotic medications, researchers also considered the impact of decreasing the amount of drugs used to sleep treat disorders. The participant had better sleep satisfaction, from no preference (mean 1.5, SD 0.7) to good (mean 2.0, SD 0.0), based on the result of a Likert scale change (score range between $0=$ "very bad" and 3="very good").

Koffel et al [62] recruited from the general population to conduct a RCT to determine the feasibility and acceptability of CBT-I coach apps. A total of 18 participants evaluated their ISI scores at each therapy session (five times), and also reported the adherence rate. We did not perform a $t$ test because there was no distinguishable statistic of ISI included in the article. However, ISI scores tended to decrease based on figures that were analyzed by hierarchical linear models. There was a significant difference $\left(t_{15}=3.04, P=.008\right)$ in ISI scores between baseline and after the third session, even though the standard CBT-I group had lower ISI scores than the app users group.

\section{Lack of Data for Performing Meta-Analysis}

Although meta-analysis is a great way to examine the effectiveness of interventions with a specific parameter, we did not have enough articles to conduct a meta-analysis. Sleep measurements were not included in all articles selected for the systematic literature review. Because more than four articles were required to perform a meta-analysis, according to Table 2 , there were not enough articles when stratified by sleep measurement and study design. Also, a sample size of $\mathrm{N}=2$ or
$\mathrm{N}=3$ is insufficient to perform the publication bias test (Begg rank correlation test or Egger regression test) and to determine the level of heterogeneity.

\section{Discussion}

\section{Summary of Evidence}

The purpose of our systematic review was to investigate whether mobile phones are a feasible and usable tool to improve sleep disorders and sleep quality in intervention studies. We also assumed that auxiliary mobile phone use helps to enhance the performance of existing intervention methods.

This review presented the articles based on two intervention methods. The first method was utilizing mobile phone apps and the second was conventional mobile phone support through telephone calls or text messages. Although many mobile phone apps were used independently, the conventional mobile phone supporting methods were (1) to use the mobile phone itself as only an intervention tool (eg teleconferencing or telecounseling), or (2) to combine with another treatment (eg, CBT-I, CBT-B, and CPAP) to enhance the effectiveness of sleep interventions. In our review, six studies were related to CBT-I $[13,15,46,57,61,62]$ and three studies to CPAP $[38,54,64]$. This indicated that sleep intervention studies using mobile phones have been developed based on the standard treatment, which has already shown reliability [33,53,71-73].

Among the sleep outcome measurements, PSQI was the most frequently reported, and PSQI scores of all seven studies $[13,21,22,55,57,61,70]$ were significantly decreased in the intervention group using mobile phones compared to standard treatment and a waitlist group. Participants in the intervention groups with mobile phones had a mean decrease in PSQI scores of 1.73 points compared to the waitlist group, and a mean decrease of 0.97 points compared to other treatment groups. Although the difference of PSQI was statistically significant, clinicians must consider the clinical significance of a one-point change in PSQI scores. According to the Buysse et al [74], a score of 5 of 21 is the cut-off point for poor sleep. Thus, the clinical significance of a one-point difference depends on the baseline score.

The ISI was the second most frequently used sleep outcome measurement tool, and all five articles using the measure $[15,57,59,61,62]$ found a statistically significant decrease in ISI score in the mobile phone use intervention group compared to non-mobile phone use group. Participants in the intervention group with mobile phones had a mean decrease in ISI scores of 5.09 points compared to the waitlist groups [57,59,62], and a mean decrease of 3.2 points in ISI scores compared to other treatments $[57,59,61]$. Because a change of 7 points in the ISI is interpreted as a different level of insomnia, a 3- or 5-point decrease in ISI scores might be considered a critical improvement. Although ESS, WASO, SOL, and TST were included in at least four studies, there was at least more than one study that reported a lack of statistical significance of intervention effect $[15,38,41,54,57,59,61]$. Therefore, ISI and PSQI seem to be the most applicable measurement tools to 
investigate the effect of mobile phone intervention on sleep disorders.

In general, $87.5 \%(14 / 16)$ of the studies $[15,21,22,38,41,54,55,57,59,61,62,64,67,70]$ reviewed supported the evidence of capability and efficacy of mobile phone usage interventions. When mobile phones were used as auxiliary equipment, the intervention that applied telephone calls or mobile phone apps clearly demonstrated equal or enhanced efficacy for sleep quality and index score compared to the traditional sleep intervention [15,38,54,55,57,59,61,64,67,70]. This difference was seen not only for the waitlist control group [54,55,57,59], but also for the telephone-supported intervention and traditional treatment $[15,38,61,64,67,70]$. The advantage of mobile phone intervention was also illustrated in apps using intervention [13,22,41,46,62] or text message interventions [21].

\section{Limitations of Review}

There are several limitations of the studies included in this review. First, there is no standardized study design, especially for the test period, procedure, and sleep intervention tools. For example, there is a limitation to use all mobile phone apps to compare each study because researchers used their own personally developed or nonpublicly available apps. As such, we were unable to make comparisons between interventions due to differences in app functions and interfaces. Due to the heterogeneity of the study design and sleep measurement tools, it was difficult to compare the effectiveness of the sleep app interventions. This will be an issue for reproducibility in further research. Second, although it is a common limitation for RCT study designs, the uniqueness of each study's target population limits further analysis and replication. For instance, results from studies with a cannabis disorder use group [13] and a post-deployment soldier with mild traumatic brain injury [70] were difficult to extrapolate to the general population. Third, there are few interventions using mobile technology that have been published in peer-reviewed journals, so we were limited with respect to the number of articles we could include in the study. Although many $t$ test for each sleep measurement showed significant effectiveness of sleep interventions, the small number of studies for subgrouping limits performing a meta-analysis. Fourth, there is the possibility of missed articles. Because the
mHealth market is growing rapidly, our search possibly missed some articles that used new mobile phone intervention tools. On the other hand, it also might be possible to miss some articles during the search stage due to the usage of different language or jargon unique to the evolving mHealth industry.

\section{Conclusion}

This study has several strengths. To the best of our knowledge, this study was the first to review the effectiveness of mobile phone interventions on sleep quality, quantity, and sleep disorders. By focusing exclusively on the mobile phone itself, it allows us to tailor future mHealth interventions for sleep. Also, our study examined various aspects of sleep measurement tools that account for sleep quality, sleep quantity, and many sleep disorders such as insomnia and sleep latency. Additionally, our study provided evidence of the potential of mobile-based interventions for improving sleep disorders. Along with current research that support the benefits of cost-efficiency of mHealth interventions, these findings provide an impetus for further research examining the empirical evidence of sleep interventions using mobile phones.

In conclusion, our systematic review supports the evidence that mobile technology-based interventions are an effective tool to improve symptoms of sleep disorders and quality of sleep than traditional intervention without mobile phone. Also, we suggest the following research design for future sleep intervention studies: (1) PSQI and ISI as sleep outcome measurements, (2) RCTs, (3) compare with standard treatment (ie, CPAP, CBT-I), and (4) compare to a waitlist control group. In addition to intervention methods, because mobile phone apps vary and many of these apps are not being studied, it is important to perform a content analysis on commercially available apps to determine common functionalities prior to undertaking interventions [75]. Our finding was not only applicable to those with sleep disorders who need clinical care, but also to medical professionals who are interested in ways to determine effective sleep interventions. Moving forward, app developers and sleep experts need to develop evidence-based guidelines with behavioral change components for sleep apps to maximize their efficacy and to take advantage of mobile phones to apply to existing standard treatments for sleep interventions.

\section{Acknowledgments}

The authors would like to thank Dr Ruopeng An for his advice regarding systematic reviews.

\section{Authors' Contributions}

JCS contributed to the concept and design for the current study, performed data analyses, and drafted the manuscript. JK participated in conception and design, data analysis of review procedure, and provided critical feedback on the draft of the manuscript. DGT provided guidance and critical feedback on the concept of the study and drafts of the manuscript. All authors contributed critical revision of the manuscript for important intellectual content and read and approved the final manuscript.

\section{Conflicts of Interest}

None declared.

\section{Multimedia Appendix 1}

Searching Keywords. 
[PDF File (Adobe PDF File), 15KB-Multimedia Appendix 1]

\section{Multimedia Appendix 2}

Quality Assessment Score.

\section{[PDF File (Adobe PDF File), 26KB-Multimedia Appendix 2]}

\section{References}

1. Altevogt B, Colten H. Sleep Disorders and Sleep Deprivation: An Unmet Public Health Problem. Washington, DC: National Academies Press; 2006.

2. Cleveland Clinic. 2013. Common sleep disorders URL: https://my.clevelandclinic.org/health/articles/common-sleep-disorders [accessed 2017-02-18]

3. Gottlieb DJ, Yenokyan G, Newman AB, O'Connor GT, Punjabi NM, Quan SF, et al. Prospective study of obstructive sleep apnea and incident coronary heart disease and heart failure: the sleep heart health study. Circulation $2010 \mathrm{Jul}$ 27;122(4):352-360 [FREE Full text] [doi: 10.1161/CIRCULATIONAHA.109.901801] [Medline: 20625114]

4. Cappuccio FP, Taggart FM, Kandala N, Currie A, Peile E, Stranges S, et al. Meta-analysis of short sleep duration and obesity in children and adults. Sleep 2008 May;31(5):619-626 [FREE Full text] [Medline: 18517032]

5. Gangwisch JE, Heymsfield SB, Boden-Albala B, Buijs RM, Kreier F, Pickering TG, et al. Sleep duration as a risk factor for diabetes incidence in a large U.S. sample. Sleep 2007 Dec;30(12):1667-1673 [FREE Full text] [Medline: 18246976]

6. Macey PM, Woo MA, Kumar R, Cross RL, Harper RM. Relationship between obstructive sleep apnea severity and sleep, depression and anxiety symptoms in newly-diagnosed patients. PLoS One 2010 Apr 16;5(4):e10211 [FREE Full text] [doi: 10.1371/journal.pone.0010211] [Medline: 20419135]

7. Markwald RR, Melanson EL, Smith MR, Higgins J, Perreault L, Eckel RH, et al. Impact of insufficient sleep on total daily energy expenditure, food intake, and weight gain. Proc Natl Acad Sci U S A 2013 Apr 02;110(14):5695-5700 [FREE Full text] [doi: 10.1073/pnas.1216951110] [Medline: 23479616]

8. Möller-Levet CS, Archer S, Bucca G, Laing EE, Slak A, Kabiljo R, et al. Effects of insufficient sleep on circadian rhythmicity and expression amplitude of the human blood transcriptome. Proc Natl Acad Sci U S A 2013 Mar 19;110(12):E1132-E1141 [FREE Full text] [doi: 10.1073/pnas.1217154110] [Medline: 23440187]

9. Gottlieb DJ, Redline S, Nieto FJ, Baldwin CM, Newman AB, Resnick HE, et al. Association of usual sleep duration with hypertension: The sleep heart health study. Sleep 2006 Aug;29(8):1009-1014. [Medline: 16944668]

10. Chaput J, Després JP, Bouchard C, Astrup A, Tremblay A. Sleep duration as a risk factor for the development of type 2 diabetes or impaired glucose tolerance: analyses of the Quebec Family Study. Sleep Med 2009 Sep;10(8):919-924. [doi: 10.1016/j.sleep.2008.09.016] [Medline: 19332380]

11. National Center for Health Statistics. Table SLP-2. Adults aged 18 and over who met the Healthy People 2020 objective for sufficient sleep, by sex and selected characteristics: United States, annualized, 2011-2014. 2016. URL: https://ftp. cdc.gov/pub/Health Statistics/NCHS/NHIS/SHS/2011-2014 AHB Table SLP-2.pdf [accessed 2017-07-26] [WebCite Cache ID 6sGCJt8Y6]

12. National Sleep Foundation. 2011 Mar 7. Annual Sleep in America poll exploring connections with communications technology use and sleep URL: https://sleepfoundation.org/media-center/press-release/ annual-sleep-america-poll-exploring-connections-communications-technology-use- [accessed 2017-07-27] [WebCite Cache ID 6sGD0sPz3]

13. Babson K, Ramo D, Baldini L, Vandrey R, Bonn-Miller M. Mobile app-delivered cognitive behavioral therapy for insomnia: feasibility and initial efficacy among veterans with cannabis use disorders. JMIR Res Protoc 2015 Jul 17;4(3):e87 [FREE Full text] [doi: 10.2196/resprot.3852] [Medline: 26187404]

14. Holmqvist M, Vincent N, Walsh K. Web- vs. telehealth-based delivery of cognitive behavioral therapy for insomnia: a randomized controlled trial. Sleep Med 2014 Feb;15(2):187-195. [doi: 10.1016/j.sleep.2013.10.013] [Medline: 24461370]

15. Lichstein K, Scogin F, Thomas S, DiNapoli E, Dillon H, McFadden A. Telehealth cognitive behavior therapy for co-occurring insomnia and depression symptoms in older adults. J Clin Psychol 2013 Oct;69(10):1056-1065 [FREE Full text] [doi: 10.1002/jclp.22030] [Medline: 24014056]

16. Munafo D, Hevener W, Crocker M, Willes L, Sridasome S, Muhsin M. A telehealth program for CPAP adherence reduces labor and yields similar adherence and efficacy when compared to standard of care. Sleep Breath 2016 May;20(2):777-785 [FREE Full text] [doi: 10.1007/s11325-015-1298-4] [Medline: 26754933]

17. Sparrow D, Aloia M, Demolles D, Gottlieb D. A telemedicine intervention to improve adherence to continuous positive airway pressure: a randomised controlled trial. Thorax 2010 Dec;65(12):1061-1066. [doi: 10.1136/thx.2009.133215] [Medline: 20880872]

18. Nicholas J, Larsen M, Proudfoot J, Christensen H. Mobile apps for bipolar disorder: a systematic review of features and content quality. J Med Internet Res 2015 Aug 17;17(8):e198 [FREE Full text] [doi: 10.2196/jmir.4581] [Medline: 26283290] 
19. Bakker D, Kazantzis N, Rickwood D, Rickard N. Mental health smartphone apps: review and evidence-based recommendations for future developments. JMIR Ment Health 2016 Mar 01;3(1):e7 [FREE Full text] [doi: 10.2196/mental.4984] [Medline: 26932350]

20. American Telemedicine Association Pediatric Special Interest Group. American Academy of Pediatrics. What is telehealth? URL: https://www.aap.org/en-us/professional-resources/practice-transformation/telehealth/Pages/What-is-Telehealth.aspx [accessed 2017-07-27] [WebCite Cache ID 6sGDYVrTX]

21. Filion A, Darlington G, Chaput J, Ybarra M, Haines J. Examining the influence of a text message-based sleep and physical activity intervention among young adult smokers in the United States. BMC Public Health 2015 Jul 16;15:671 [FREE Full text] [doi: 10.1186/s12889-015-2045-2] [Medline: 26178640]

22. van Drongelen A, Boot CR, Hlobil H, Twisk JW, Smid T, van der Beek AJ. Evaluation of an mHealth intervention aiming to improve health-related behavior and sleep and reduce fatigue among airline pilots. Scand J Work Environ Health 2014 Nov;40(6):557-568 [FREE Full text] [doi: 10.5271/sjweh.3447] [Medline: 25121620]

23. Bhat S, Ferraris A, Gupta D, Mozafarian M, DeBari VA, Gushway-Henry N, et al. Is there a clinical role for smartphone sleep apps? comparison of sleep cycle detection by a smartphone application to polysomnography. J Clin Sleep Med 2015 Jul 15;11(7):709-715 [FREE Full text] [doi: 10.5664/jcsm.4840] [Medline: 25766719]

24. Stippig A, Hübers U, Emerich M. Apps in sleep medicine. Sleep Breath 2015 Mar;19(1):411-417. [doi: 10.1007/s11325-014-1009-6] [Medline: 24888483]

25. Krisch JA. The New York Times. 2015 Mar 16. Questioning the value of health apps URL: https://well.blogs.nytimes.com/ 2015/03/16/health-apps-provide-pictures-if-not-proof-of-health/?_r=1 [accessed 2017-07-27] [WebCite Cache ID 6sGDx081D]

26. Research 2 Guidance. mHealth App Developer Ecomomics 2016. 2016 Oct. URL: https://research2guidance.com/r2g/ r2g-mHealth-App-Developer-Economics-2016.pdf [accessed 2017-07-27] [WebCite Cache ID 6sGEeCCym]

27. Behar J, Roebuck A, Domingos J, Gederi E, Clifford G. A review of current sleep screening applications for smartphones. Physiol Meas 2013 Jul;34(7):R29-R46. [doi: 10.1088/0967-3334/34/7/R29] [Medline: 23771214]

28. Ko P, Kientz J, Choe E, Kay M, Landis C, Watson N. Consumer sleep technologies: a review of the landscape. J Clin Sleep Med 2015 Dec 15;11(12):1455-1461 [FREE Full text] [doi: 10.5664/jcsm.5288] [Medline: 26156958]

29. Kolla B, Mansukhani S, Mansukhani M. Consumer sleep tracking devices: a review of mechanisms, validity and utility. Expert Rev Med Devices 2016 May;13(5):497-506. [doi: 10.1586/17434440.2016.1171708] [Medline: 27043070]

30. Lee J, Finkelstein J. Consumer sleep tracking devices: a critical review. Stud Health Technol Inform 2015;210:458-460. [Medline: 25991187]

31. Zia S, Fields B. Sleep telemedicine: an emerging field's latest frontier. Chest 2016 Jun;149(6):1556-1565. [doi: 10.1016/j.chest.2016.02.670] [Medline: 26970035]

32. Donker T, Petrie K, Proudfoot J, Clarke J, Birch M, Christensen H. Smartphones for smarter delivery of mental health programs: a systematic review. J Med Internet Res 2013 Nov 15;15(11):e247 [FREE Full text] [doi: 10.2196/jmir.2791] [Medline: 24240579]

33. Sawyer AM, Gooneratne NS, Marcus CL, Ofer D, Richards KC, Weaver TE. A systematic review of CPAP adherence across age groups: clinical and empiric insights for developing CPAP adherence interventions. Sleep Med Rev 2011 Dec;15(6):343-356 [FREE Full text] [doi: 10.1016/j.smrv.2011.01.003] [Medline: 21652236]

34. Verbraecken J. Applications of evolving technologies in sleep medicine. Breathe 2013 Dec 01;9(6):442-455. [doi: 10.1183/20734735.012213]

35. Anjarwalla T. CNN. 2010 Jul 9. Inventor of cell phone: we knew someday everybody would have one URL: http://www. $\underline{\text { cnn.com/2010/TECH/mobile/07/09/cooper.cell.phone.inventor/index.html [accessed 2017-07-27] [WebCite Cache ID }}$ 6sGFJWTMx]

36. Moher D, Liberati A, Tetzlaff J, Altman DG, PRISMA Group. Preferred reporting items for systematic reviews and meta-analyses: the PRISMA statement. PLoS Med 2009 Jul 21;6(7):e1000097 [FREE Full text] [doi: 10.1371/journal.pmed.1000097] [Medline: 19621072]

37. Zhu H, An R. Impact of home-delivered meal programs on diet and nutrition among older adults: a review. Nutr Health 2013 Apr;22(2):89-103. [doi: 10.1177/0260106014537146] [Medline: 24916974]

38. Anttalainen U, Melkko S, Hakko S, Laitinen T, Saaresranta T. Telemonitoring of CPAP therapy may save nursing time. Sleep Breath 2016 Dec;20(4):1209-1215. [doi: 10.1007/s11325-016-1337-9] [Medline: 27043327]

39. Arora T, Broglia E, Thomas GN, Taheri S. Associations between specific technologies and adolescent sleep quantity, sleep quality, and parasomnias. Sleep Med 2014 Feb;15(2):240-247. [doi: 10.1016/j.sleep.2013.08.799] [Medline: 24394730]

40. Baig M, Antonescu-Turcu A, Ratarasarn K. Impact of sleep telemedicine protocol in management of sleep apnea: a 5-year VA experience. Telemed J E Health 2016 May;22(5):458-462. [doi: 10.1089/tmj.2015.0047] [Medline: 26974884]

41. Bauer JS, Consolvo S, Greenstein B, Schooler J, Wu E, Watson NF, et al. ShutEye: encouraging awareness of healthy sleep recommendations with a mobile, peripheral display. In: Proceedings of the SIGCHI Conference on Human Factors in Computing Systems. 2012 May 5 Presented at: CHI '12: SIGCHI Conference on Human Factors in Computing Systems; May 5-10, 2012; Austin, TX p. 1401-1410. 
42. Blom K, Tarkian TH, Wiklund T, Danlycke E, Forssén M, Söderström A, et al. Internet-vs. group-delivered cognitive behavior therapy for insomnia: a randomized controlled non-inferiority trial. Behav Res Ther 2015 Jul;70:47-55 [FREE Full text] [doi: 10.1016/j.brat.2015.05.002] [Medline: 25981329]

43. Buman MP, Epstein DR, Gutierrez M, Herb C, Hollingshead K, Huberty JL, et al. BeWell24: development and process evaluation of a smartphone "app" to improve sleep, sedentary, and active behaviors in US Veterans with increased metabolic risk. Transl Behav Med 2016 Sep;6(3):438-448 [FREE Full text] [doi: 10.1007/s13142-015-0359-3] [Medline: 27528532]

44. Camacho M, Chang ET, Fernandez-Salvador C, Capasso R. Treatment of snoring with a nasopharyngeal airway tube. Case Rep Med 2016;2016:3628716 [ [FREE Full text] [doi: 10.1155/2016/3628716] [Medline: 27795710]

45. Cavalera C, Pagnini F, Rovaris M, Mendozzi L, Pugnetti L, Garegnani M, et al. A telemedicine meditation intervention for people with multiple sclerosis and their caregivers: study protocol for a randomized controlled trial. Trials 2016 Jan 04;17:4 [FREE Full text] [doi: 10.1186/s13063-015-1136-9] [Medline: 26729330]

46. Chen Y, Hung Y, Chen H. Mobile application-assisted cognitive behavioral therapy for insomnia in an older adult. Telemed J E Health 2016 Apr;22(4):332-334. [doi: 10.1089/tmj.2015.0064] [Medline: 26393902]

47. Cho YM, Lim HJ, Jang H, Kim K, Choi JW, Shin C, et al. A follow-up study of the association between mobile phone use and symptoms of ill health. Environ Health Toxicol 2016;32:e2017001 [FREE Full text] [doi: 10.5620/eht.e2017001] [Medline: 28111420]

48. Craven O, Hughes CA, Burton A, Saunders MP, Molassiotis A. Is a nurse-led telephone intervention a viable alternative to nurse-led home care and standard care for patients receiving oral capecitabine? Results from a large prospective audit in patients with colorectal cancer. Eur J Cancer Care (Engl) 2013 May;22(3):413-419. [doi: 10.1111/ecc.12047] [Medline: 23527965]

49. Cvengros JA. One size does not fit all: matching patients with insomnia treatment modality. Sleep Med 2014 Feb;15(2):161-162. [doi: 10.1016/j.sleep.2013.12.002] [Medline: 24434167]

50. van Drongelen A, van der Beek AJ, Hlobil H, Smid T, Boot C. Development and evaluation of an intervention aiming to reduce fatigue in airline pilots: design of a randomised controlled trial. BMC Public Health 2013 Aug 26;13:776 [FREE Full text] [doi: 10.1186/1471-2458-13-776] [Medline: 23971514]

51. Duncan M, Vandelanotte C, Trost S, Rebar AL, Rogers N, Burton NW, et al. Balanced: a randomised trial examining the efficacy of two self-monitoring methods for an app-based multi-behaviour intervention to improve physical activity, sitting and sleep in adults. BMC Public Health 2016 Jul 30;16:670 [FREE Full text] [doi: 10.1186/s12889-016-3256-x] [Medline: 27473327]

52. Eaton LH, Gordon DB, Wyant S, Theodore BR, Meins AR, Rue T, et al. Development and implementation of a telehealth-enhanced intervention for pain and symptom management. Contemp Clin Trials 2014 Jul;38(2):213-220 [FREE Full text] [doi: 10.1016/j.cct.2014.05.005] [Medline: 24846620]

53. Espie C, Hames P, McKinstry B. Use of the Internet and mobile media for delivery of cognitive behavioral insomnia therapy. Sleep Medicine Clinics 2013 Sep;8(3):407-419. [doi: 10.1016/j.jsmc.2013.06.001]

54. Fox N, Hirsch-Allen A, Goodfellow E, Wenner J, Fleetham J, Ryan CF, et al. The impact of a telemedicine monitoring system on positive airway pressure adherence in patients with obstructive sleep apnea: a randomized controlled trial. Sleep 2012 Apr 01;35(4):477-481 [FREE Full text] [doi: 10.5665/sleep.1728] [Medline: 22467985]

55. Freeman LW, White R, Ratcliff CG, Sutton S, Stewart M, Palmer JL, et al. A randomized trial comparing live and telemedicine deliveries of an imagery-based behavioral intervention for breast cancer survivors: reducing symptoms and barriers to care. Psychooncology 2015 Aug;24(8):910-918 [FREE Full text] [doi: 10.1002/pon.3656] [Medline: 25146413]

56. Gehrman P, Shah MT, Miles A, Kuna S, Godleski L. Feasibility of group cognitive-behavioral treatment of insomnia delivered by clinical video telehealth. Telemed J E Health 2016 Dec;22(12):1041-1046. [doi: 10.1089/tmj.2016.0032] [Medline: 27286369]

57. Ho FY, Chung K, Yeung W, Ng TH, Cheng SK. Weekly brief phone support in self-help cognitive behavioral therapy for insomnia disorder: Relevance to adherence and efficacy. Behav Res Ther 2014 Dec;63:147-156. [doi:

10.1016/j.brat.2014.10.002] [Medline: 25461790]

58. Isetta V, Negrín MA, Monasterio C, Masa JF, Feu N, Álvarez A, Spanish Sleep Network. A Bayesian cost-effectiveness analysis of a telemedicine-based strategy for the management of sleep apnoea: a multicentre randomised controlled trial. Thorax 2015 Nov;70(11):1054-1061. [doi: 10.1136/thoraxjnl-2015-207032] [Medline: 26310452]

59. Jernelöv S, Lekander M, Blom K, Rydh S, Ljótsson B, Axelsson J, et al. Efficacy of a behavioral self-help treatment with or without therapist guidance for co-morbid and primary insomnia--a randomized controlled trial. BMC Psychiatry 2012 Jan 22;12:5 [FREE Full text] [doi: 10.1186/1471-244X-12-5] [Medline: 22264332]

60. Filion AJ, Darlington G, Chaput JP, Ybarra M, Haines J. Examining the influence of a text message-based sleep and physical activity intervention among young adult smokers in the United States. BMC Public Health 2015 Jul 16;15:671 [FREE Full text] [doi: 10.1186/s12889-015-2045-2] [Medline: 26178640]

61. Kauffman R. Telephone-based CBT reduced insomnia severity more than menopause education in menopausal women. Ann Intern Med 2016 Sep 20;165(6):JC30. [doi: 10.7326/ACPJC-2016-165-6-030] [Medline: 27653727]

62. Koffel E, Kuhn E, Petsoulis N, Erbes CR, Anders S, Hoffman JE, et al. A randomized controlled pilot study of CBT-I Coach: feasibility, acceptability, and potential impact of a mobile phone application for patients in cognitive behavioral 
therapy for insomnia. Health Informatics J 2016 Jun 27:1460458216656472. [doi: 10.1177/1460458216656472] [Medline: 27354394]

63. Mason EC, Harvey AG. Insomnia before and after treatment for anxiety and depression. J Affect Disord 2014 Oct;168:415-421. [doi: 10.1016/j.jad.2014.07.020] [Medline: 25108278]

64. Mendelson M, Vivodtzev I, Tamisier R, Laplaud D, Dias-Domingos S, Baguet JP, et al. CPAP treatment supported by telemedicine does not improve blood pressure in high cardiovascular risk OSA patients: a randomized, controlled trial. Sleep 2014 Nov 01;37(11):1863-1870 [FREE Full text] [doi: 10.5665/sleep.4186] [Medline: 25364081]

65. Salaffi F, Ciapetti A, Gasparini S, Atzeni F, Sarzi-Puttini P, Baroni M. Web/Internet-based telemonitoring of a randomized controlled trial evaluating the time-integrated effects of a 24-week multicomponent intervention on key health outcomes in patients with fibromyalgia. Clin Exp Rheumatol 2015;33(1 Suppl 88):S93-S101. [Medline: 25786050]

66. Sedkaoui K, Leseux L, Pontier S, Rossin N, Leophonte P, Fraysse JL, et al. Efficiency of a phone coaching program on adherence to continuous positive airway pressure in sleep apnea hypopnea syndrome: a randomized trial. BMC Pulm Med 2015 Sep 14;15:102 [FREE Full text] [doi: 10.1186/s12890-015-0099-7] [Medline: 26370444]

67. Stremler R, Hodnett E, Lee K, MacMillan S, Mill C, Ongcangco L, et al. A behavioral-educational intervention to promote maternal and infant sleep: a pilot randomized, controlled trial. Sleep 2006 Dec;29(12):1609-1615. [Medline: 17252892]

68. Taylor Y, Eliasson A, Andrada T, Kristo D, Howard R. The role of telemedicine in CPAP compliance for patients with obstructive sleep apnea syndrome. Sleep Breath 2006 Sep;10(3):132-138. [doi: 10.1007/s11325-006-0059-9] [Medline: 16565867]

69. Van Devender M, Shang Y. Wake IQ: using a smartphone to reduce sleep inertia. 2013 Jan Presented at: IEEE Consumer Communications and Networking Conference; Jan 11-14, 2013; Las Vegas, NV.

70. Vuletic S, Bell KR, Jain S, Bush N, Temkin N, Fann JR, CONTACT Investigators. Telephone problem-solving treatment improves sleep quality in service members with combat-related mild traumatic brain injury: results from a randomized clinical trial. J Head Trauma Rehabil 2016;31(2):147-157. [doi: 10.1097/HTR.0000000000000221] [Medline: 26959668]

71. Coma-Del-Corral MJ, Alonso-Álvarez ML, Allende M, Cordero J, Ordax E, Masa F, et al. Reliability of telemedicine in the diagnosis and treatment of sleep apnea syndrome. Telemed J E Health 2013 Jan;19(1):7-12 [FREE Full text] [doi: 10.1089/tmj.2012.0007] [Medline: 23186084]

72. Bang M, Timpka T, Eriksson H, Holm E, Nordin C. Mobile phone computing for in-situ cognitive behavioral therapy. Stud Health Technol Inform 2007;129(Pt 2):1078-1082. [Medline: 17911881 ]

73. Kuhn E, Weiss B, Taylor K, Hoffman JE, Ramsey KM, Manber R, et al. CBT-I Coach: a description and clinician perceptions of a mobile app for cognitive behavioral therapy for insomnia. J Clin Sleep Med 2016 Apr 15;12(4):597-606 [FREE Full text] [doi: 10.5664/jesm.5700] [Medline: 26888586]

74. Buysse D, Reynolds C, Monk T, Berman S, Kupfer D. The Pittsburgh Sleep Quality Index: a new instrument for psychiatric practice and research. Psychiatry Res 1989 May;28(2):193-213. [Medline: 2748771]

75. Grigsby-Toussaint DS, Shin JC, Reeves DM, Beattie A, Auguste E, Jean-Louis G. Sleep apps and behavioral constructs: a content analysis. Prev Med Rep 2017 Jun;6:126-129. [doi: 10.1016/j.pmedr.2017.02.018] [Medline: 28316907]

\section{Abbreviations}

AHI: Apnea-Hypopnea Index

BTS: bed time stress

CINAHL: Cumulative Index to Nursing and Allied Health Literature

CPAP: continuous positive airway pressure

DBAS: Dysfunctional Beliefs and Attitudes about Sleep Scale

ESS: Epworth Sleepiness Scale

GSDS: General Sleep Disturbance Scale

HRSD: Hamilton Rating Scale for Depression with sleep

ISI: Insomnia Severity Index

OSA: obstructive sleep apnea

PRISMA: Preferred Reporting Items for Systematic Reviews and Meta-Analysis

PSQI: Pittsburgh Sleep Quality Index

RCT: randomized controlled trial

SE: sleep efficiency

SOL: sleep-onset latency

SQ: sleep quality

SRBQ: Sleep-Related Behavior Questionnaire

SSR: Sleep Satisfaction Rate

TST: total sleep time

WASO: wakefulness after initial sleep onset 
Edited by G Eysenbach; submitted 31.12.16; peer-reviewed by YS Bin, M Zhang, J Apolinário-Hagen, J Dudeney, Y Liu; comments to author 11.02.17; revised version received 18.04.17; accepted 17.06.17; published 07.09.17

Please cite as:

Shin JC, Kim J, Grigsby-Toussaint D

Mobile Phone Interventions for Sleep Disorders and Sleep Quality: Systematic Review

JMIR Mhealth Uhealth 2017;5(9):e131

URL: http://mhealth.jmir.org/2017/9/e131/

doi: 10.2196/mhealth.7244

PMID: 28882808

CJong Cheol Shin, Julia Kim, Diana Grigsby-Toussaint. Originally published in JMIR Mhealth and Uhealth (http://mhealth.jmir.org), 07.09.2017. This is an open-access article distributed under the terms of the Creative Commons Attribution License (https://creativecommons.org/licenses/by/4.0/), which permits unrestricted use, distribution, and reproduction in any medium, provided the original work, first published in JMIR mhealth and uhealth, is properly cited. The complete bibliographic information, a link to the original publication on http://mhealth.jmir.org/, as well as this copyright and license information must be included. 